there is expert advice available through professional associations to guide those who wish to branch out into new fields of opportunity. By raising the status and improving the general welfare conditions of catering staffs, much will be achieved towards the improvement of nutritional standards.

In paragraph 8 of the Special Planning Committee's memorandum (Nutrition Society, 1945) it is said: "The profession of Dietitian will be much enriched by the recruitment of persons who have successfully controlled large scale kitchens through the searching years of war". This is quite true, but why not admit as well that the catering profession would be much enriched by the recruitment of persons who have successfully completed a course of training in dietetics?

\title{
REFERENCES
}

Institutional Management Association (1944). Report of the Committee on Training and Employment of Women in Large Scale Catering and Household Administration. London: Institutional Management Association.

Nutrition Society (1945). Brit. med. J. ii, 617.

\section{The Dietician in Hospitals}

\section{Miss J. I. Mills (The General Infirmary, Leeds)}

\section{Scope of the Work}

The scope of the work of a hospital dietician varies a good deal in different institutions throughout the country. Her responsibilities may be limited to the control and supervision of the diet kitchen and outpatient dietetic clinic, and the charge of a unit which is practically unconnected with the food service as a whole. She may, on the other hand, be entirely responsible for the catering of the hospital in all its aspects, including the administrative side, food purchasing, and preparation and service of meals to staff and patients, as well as for the general supervision of the special diet department.

Many hospitals are now endeavouring to establish a unified food service department under a catering officer who is responsible to a dietetic committee, although it is still a matter of opinion whether this person should be a qualified dietician or an executive officer with experience of large scale commercial catering. It is agreed, however, that division of control is undesirable, and this division is inevitable if the head of the catering department is not qualified as a dietician. Moreover, there is an undoubted demand for hospital dieticians with the necessary experience and ability to take charge of all aspects of the nutrition service.

The work of the hospital dietician falls into three main categories:

(1) General catering administration, staff control, control of purchasing, control of stores, food distribution;

(2) Menu planning, supervision of food preparation, food service;

(3) Therapeutic dietetics, planning, calculation and preparation of special diets including research diets, dietetic instruction of patients. 


\section{Opportunities for Teaching in Hospital}

Teaching forms another category of the work of a dietician in hospital. A large hospital catering department can offer to domestic science students practical experience in quantity cookery, to nurses in training instruction in dietetic cooking, and to student dieticians practical catering experience and instruction in dietetics.

It would be possible, in the teaching hospitals, also to arrange for tuition in the theoretical as well as the practical aspects of catering management, normal nutrition and diet in disease.

In addition, by organizing short courses of nutrition lectures, cookery demonstrations and discussions for hospital caterers in the district, the dietetic department of a large hospital can become a centre for the exchange of ideas, and for spreading knowledge of nutritional principles and catering methods.

\section{Hospital Catering}

Hospital catering involves all aspects of nutrition.

Preventive Nutrition. The feeding of the staff which forms such an important part of the work includes the preparation of meals for workers in a number of different categories with varied food requirements, such as the adolescent maid, the cleaner or laundry hand, the nurse, the sister, the resident doctor and the office worker.

Curative Nutrition. The feeding of patients includes all aspects of the use of diet in disease such as the preparation of the general or convalescent diet, the light diet, the special therapeutic diet, and infants' and children's diets. Meals for private patients usually call for more elaborate preparation and service, although the requirements are essentially the same as those of patients in the general ward. The preparation of meals to be sold for profit is seldom part of the work, unless canteens for non-resident staff are operated on a paying basis. It is necessary to consider the tastes, likes and dislikes of different categories of staff and patients, or waste of food and malnutrition will result even if meals are well balanced and attractively served. Education in good nutritional habits should therefore be included as yet another function of the hospital food service.

Organization of the Catering Staff. It can be estimated approximately that, for the catering department of a hospital of 700 to 1000 beds, the following dieticians are necessary:

(1) A catering officer or food supervisor, responsible for the general administration and control of staff, and for the purchasing, supervision, storage and distribution of food;

(2) An assistant catering officer to control the planning of menus and to supervise the preparation and service of food especially for staff meals. An assistant dietician would probably be needed to supervise the meals of the patients in the general ward, and another to supervise the meals of the private patients; 
(3) A dietician in charge of the dietetic department, responsible for the planning and calculation of special diets, for the general organization of the department, for maintaining close contact with the ward patients and with the medical and nursing staff, and for practical teaching and lectures on dietetics to student dieticians, student nurses and others. She would need a deputy assistant dietician who would be chiefly responsible for the preparation of special diets and for supervision of the practical training of nurses and students in diet kitchen cookery.

\section{Future Developments}

While it is desirable that hospitals of over 150 beds should have the services of a trained dietician, it is probable that the catering of small affiliated branch hospitals and convalescent homes will come under the general supervision of the catering officer in charge at the parent hospital. Arrangements could be made also for a dietician to visit these hospitals at frequent intervals during the week to advise on the planning of menus and so forth, and to arrange for the preparation of special diets. She would be able also to instruct patients how to carry out their dietary treatment at home.

A very great deal has yet to be done to improve the general catering arrangements in hospitals and institutions throughout the country, and many dieticians, on taking up new appointments, will probably be faced with ill arranged kitchens and stores, and antiquated equipment for food service.

Given the opportunity to advise on extensions and to draw up plans for new equipment, dieticians would have great scope for improving food service. To achieve successful results they should have had opportunities to visit many other hospitals and become familiar with different types of catering equipment, and should be able to put ideas of their own into practice.

With its vast service problem, hospital catering is undoubtedly one of the most complicated branches of large scale nutrition. As yet the ideal arrangement for the distribution and service of cooked food from the kitchen to the far distant bed in the hospital ward has not been solved. Centralization of food preparation has solved many difficulties of control of staff and supplies, but has not solved the problem of perfect food service in spite of the provision of electrically heated food trolleys and heated lifts, for it is extremely difficult to ensure that food is not kept hot too long with consequent loss of nutritive value.

It is interesting to note that in the newly built Southern Hospital in Stockholm (Cederström, 1945) the food service problem has been tackled by decentralization of the kitchens. The plan is based on two fundamental principles, that the distance from the oven to the patient's bed must be as short as possible, and that individual tastes and needs must be catered for. Branch kitchens in each ward block serve 100 patients, and each is under the control of a dietician who works in close contact with the medical and nursing staff, supervising the dietary and food service for every patient. The kitchens are connected with the wards by fast lifts, and all foods liable to suffer from cooking in bulk or prolonged standing are prepared in them, although certain items are cooked 
in a central kitchen. For this hospital of 1200 beds about 12 dieticians will be employed for the service of the patients' food alone.

In American hospitals also, many dieticians are employed in the wards to supervise the actual service of meals and special diets to the patients; it is probable that hospital food service in this country will develop along similar lines, thereby freeing the nursing staff for other duties.

Thus it can be seen that many excellent opportunities exist for valuable and interesting work in the field of hospital nutrition, and that the training and experience which may be acquired in the food service department of a large hospital embrace almost all aspects of dietetics. Unfortunately the supply of suitably qualified and experienced dieticians to fill the posts which are now available, or are likely to be in the near future, is quite insufficient to meet the growing demand. Moreover, many dieticians who have gained experience in hospitals are now being attracted to other fields before reaching the senior positions.

In spite of these difficulties, I am confident that greater results will be achieved by the efforts of dieticians actually holding administrative posts in hospitals, and in close touch with the existing conditions of work, and with the problems of feeding and staff, than by the employment of dieticians in purely advisory capacities.

I hope, therefore, that training courses will hasten to fit dieticians for these posts which are of great importance to the community, providing a constant source of interest, and an ever present stimulus towards extension and improvement.

REHERENCE

Cederström, H. (1945). Lancet, 249, 571.

\section{Discussion}

Miss E. Washington (University College Hospital, Gower Street, London, W.C.1), joint opener: The speakers today have, between them, mentioned many of the capabilities and some of the knowledge expected of a dietician. According to them a dietician must possess:

(1) Scientific knowledge including that of chemistry, physiology, biochemistry and bacteriology, to form a background for the study of nutrition;

(2) Theoretical knowledge of the principles of nutrition and their application;

(3) Practical knowledge of buying and storing food, cooking for large and small numbers, distribution and service;

(4) Knowledge of kitchen planning, and of the installation and maintenance of equipment;

(5) Knowledge of general domestic management for the proper upkeep of her departments;

(6) Teaching ability;

(7) Knowledge of statistics and possibly also of economics.

When all these attributes, which imply a combination of theoretical and practical attitudes of mind not easily encountered, must be combined with the personal qualities of administrative ability, tact, and a voL. 4, 1946] 